\title{
Reflexões éticas e legais sobre a prática odontológica em tempos de pandemia de COVID-19
}

\author{
Ethical and legal issues in dental practice during \\ the COVID-19 pandemic
}

\author{
Felipe de Almeida Pinheiro', Marcos Vinicius Coltri ${ }^{2}$, Julia Gabriela \\ Dietrichkeit Pereira ${ }^{3}$, Ricardo Henrique Alves da Silva ${ }^{4}$
}

DOI: http://dx.doi.org/10.11606/issn.2317-2770.v26i1p27-35

\begin{abstract}
Pinheiro FA, Coltri MV, Pereira JGD, Silva RHA. Reflexões éticas e legais sobre a prática odontológica em tempos de pandemia de COVID-19. Saúde, Ética \& Justiça. 2021;26(1):27-35.

RESUMO: Em março de 2020 foi declarada pela Organização Mundial da Saúde a pandemia da doença COVID-19, causada pelo vírus SARS-CoV-2. Como estratégia para minimizar a transmissão da doença, órgãos públicos e entidades de saúde publicaram novas resoluções, notas técnicas, recomendações e protocolos referentes à prática odontológica. $\mathrm{O}$ objetivo do estudo foi abordar as implicações das normativas referentes à pandemia de COVID-19 no exercício profissional e discuti-las com as disposições éticas e legais vigentes, a fim de auxiliar na conduta segura dos cirurgiões-dentistas nesse período. Concluiu-se que embora o distanciamento social seja considerado uma das estratégias principais para prevenir a transmissão viral durante a pandemia de COVID-19, garantir o funcionamento de serviços odontológicos é imprescindível para a promoção da saúde populacional. Assim, o atendimento odontológico é viável, quando necessário e permitido, e se forem seguidos todos os preceitos éticos e legais para atuação, o profissional pode afastar a possibilidade de se envolver em processos judiciais provenientes desses atendimentos.
\end{abstract}

DESCRITORES: COVID-19; Odontologia; Legislação Odontológica; Ética Odontológica.

1. Universidade de São Paulo. Faculdade de Odontologia de Ribeirão Preto.

2. ABRADIMED - Academia Brasileira de Direito Médico.

3. Universidade de São Paulo. Faculdade de Medicina de Ribeirão Preto. Departamento de Patologia e Medicina Legal.

4. Universidade de São Paulo. Faculdade de Odontologia de Ribeirão Preto. Departamento de Estomatologia, Saúde Coletiva e Odontologia Legal.

Endereço para correspondência: Prof. Dr. Ricardo Henrique Alves da Silva. E-mail: ricardohenrique@usp.br 


\section{INTRODUÇÃO}

$\mathrm{E}$ m março de 2020 foi declarada pela Organização Mundial da Saúde a pandemia da doença COVID-19, causada pelo vírus SARS-CoV-2. A ausência de drogas antivirais efetivas, a presença de portadores assintomáticos e a alta transmissibilidade do vírus contribuíram para a sua rápida disseminação ${ }^{1}$. A transmissão do vírus pode ocorrer de forma direta, por meio da inalação de gotículas e aerossóis provenientes da tosse ou do espirro, ou por contato com a mucosa nasal, bucal ou ocular ${ }^{2}$, sendo o período de incubação estimado entre um e 14 dias $^{3}$. Amostras de saliva apresentam uma das principais fontes de propagação e transmissão da doença ${ }^{4,5}$. Assim, há de se considerar a possibilidade de transmissão e contaminação cruzada por meio de gotículas e aerossóis gerados durante os atendimentos odontológicos ${ }^{6}$.

No Brasil, o primeiro caso de COVID-19 foi notificado no estado de São Paulo em 26 de fevereiro de 2020, e como estratégia para minimizar a transmissão da doença, foi recomendada a suspensão da rotina de atendimentos odontológicos eletivos em todo o país ${ }^{7,8}$. Após seis meses, o número de casos já passava de três milhões, e ainda assim, o distanciamento social foi flexibilizado, viabilizando o funcionamento completo de consultórios $\mathrm{e}$ serviços odontológicos?.

As particularidades da assistência odontológica no contexto de pandemia fizeram com que muitos cirurgiões-dentistas modificassem seus protocolos de atendimento, gerando uma alteração significativa na rotina dos consultório ${ }^{10}$. Orientações que visam a proteção e a mitigação do risco de contaminação de profissionais e pacientes vêm sendo constantemente atualizadas por órgãos nacionais e internacionais relacionados aos serviços de saúde, como a Agência Nacional de Vigilância Sanitária (ANVISA), vinculada ao Ministério da Saúde ${ }^{11}$, a American Dental Association ${ }^{12}$ e o Center for Disease Control and Prevention $^{13,14}$.

Considerando que os órgãos públicos e as entidades de saúde publicaram novas resoluções, notas técnicas, recomendações e protocolo referentes à prática odontológica diante da pandemia de COVID-19 11 11-13,15-17 , o objetivo deste estudo foi abordar os aspectos éticos e legais do atendimento odontológico neste contexto e seus reflexos futuros, além de propor orientações aos cirurgiões-dentistas em relação aos atendimentos, auxiliando na tomada de decisões e no gerenciamento de riscos.

\section{DESENVOLVIMENTO}

\section{Autorização para o Funcionamento de Serviços Odon- tológicos}

Em situações de pandemia, como estratégia para evitar o aumento dos casos da doença, recomenda-se di- minuir a circulação de pessoas e reduzir a execução de atividades, bem como de procedimentos médicos e odontológicos associados a uma maior transmissibilidade ${ }^{18}$. Diversos órgãos internacionais de saúde se manifestaram em relação às restrições aos atendimentos odontológicos: a British Dental Association recomendou a suspensão completa de todos os procedimentos em odontologia; a American Dental Association recomendou a suspensão de procedimentos eletivos e o funcionamento apenas em casos de emergência e urgência ${ }^{12}$.

Essa divergência pode ser explicada pela responsabilidade ética e legal dos prestadores de serviços odontológicos, que devem equilibrar tanto as necessidades individuais do paciente quanto a situação epidemiológica do momento ${ }^{18}$. Outro motivo seria a diferença do cenário e do número de casos experienciados em cada país ou região. Em lugares sem casos notificados da doença, cirurgiões-dentistas mantiveram seus atendimentos normais, mesmo sem o controle da transmissão do vírus nas demais regiões ${ }^{19}$.

No Brasil, quando o primeiro caso de COVID-19 foi notificado, essas recomendações divergentes fizeram com que profissionais tivessem dúvidas sobre a conduta adequada. Em busca de respostas, os profissionais consultaram os atos normativos dos Conselhos Federal e Regionais de Odontologia, todavia, esses Conselhos realizam a supervisão da ética profissional, não lhes cabendo legislar sobre o funcionamento de serviços odontológicos ${ }^{20}$. No Brasil, os gestores municipais, estaduais e federais possuem a competência de legislar e a autonomia para definir o funcionamento dos serviços de saúde no território sob sua jurisdição, devendo basear-se nas características e particularidades epidemiológicas de cada localidade ${ }^{15}$. A esses gestores, cabe considerar as recomendações das autoridades de saúde pública nacional e locais e das melhores evidências científicas ${ }^{11}$.

A ANVISA recomendou que atendimentos odontológicos eletivos fossem adiados, restringindo o atendimento clínico apenas aos casos de urgência e emergência $^{11}$. Em complemento, a Associação de Medicina Intensiva Brasileira (AMIB), junto com o Conselho Federal de Odontologia (CFO), recomendou que pacientes com suspeita ou com COVID-19 necessitando de atendimento de urgência e emergência deviam ter o tratamento realizado com precauções de biossegurança para toda a equipe ${ }^{16}$. Vale ressaltar que estas não têm poder de lei, mas embasam a tomada de decisão pelos gestores competentes. Sendo assim, no contexto de pandemia, para saber se há alguma orientação que impeça o exercício das atividades profissionais, faz-se necessária a verificação do estágio de vigência dos decretos e das leis municipais, estaduais e federais $^{14,21}$.

Quando não houver restrição dos atendimentos em âmbito legal, escolher atender ou não um paciente durante a pandemia passa a ser um dilema ético. E para essa tomada de decisão, os cirurgiões-dentistas devem embasar-se 
no dever fundamental de zelar pela saúde e pela dignidade do paciente ${ }^{22}$, e nos princípios bioéticos da beneficência e não maleficência, devendo promover saúde para o paciente sem expô-lo ao risco de sofrer algum dano ${ }^{23}$.

\section{Classificação dos Tratamentos Odontológicos}

As emergências odontológicas são condições potencialmente fatais que exigem tratamento imediato ${ }^{12,16,19}$. Já as urgências odontológicas não apresentam risco de morte, porém necessitam de intervenção profissional imediata para que o caso não se agrave e evolua para uma situação de emergência ${ }^{18}$. Os tratamentos eletivos, por sua vez, são aqueles que podem ser postergados sem riscos para o paciente ${ }^{16}$.

$\mathrm{Na}$ odontologia, classificam-se como situações de emergência a hemorragia descontrolada e as situações que podem comprometer as vias aéreas dos pacientes, como infecções difusas de tecidos moles (celulites) ou traumas envolvendo os ossos da face ${ }^{12,16}$. Os casos de urgência, por outro lado, caracterizam-se por: dor severa ${ }^{19}$; pulpite irreversível; pericoronarite; alveolite e osteíte pós-operatórias; abscesso dental e infecções localizadas; fraturas dentais associadas a dor e a lesões nos tecidos moles; avulsão e luxação dental; confecção de restaurações provisórias em casos de perda ou fratura; lesões de cáries extensas; remoção de suturas; ajustes de próteses em pacientes sob tratamento oncológico; tratamento de mucosites; ajustes de próteses por motivos funcionais; substituição de curativo de demora em dentes com acesso e sintomatologia dolorosa; e ajustes de aparelhos ortodônticos que estejam lesionando a mucosa bucal ${ }^{12,16}$.

Já os tratamentos eletivos são os exames clínicos iniciais ou de manutenção; a realização de radiografias de rotina; profilaxia; limpezas dentais de rotina; extração de dentes assintomáticos; tratamento de lesões de cárie inativas e assintomáticas; procedimentos ortodônticos e de dentística restauradora estéticos ${ }^{12,16}$; e tratamentos endodônticos, sendo recomendado apenas o acesso e a medicação intracanal ${ }^{18}$.

A manutenção de atendimentos de urgência e emergência em consultórios ou clínicas odontológicas é importante, pois limitar o acesso ao atendimento odontológico nesses estabelecimentos faz com que pacientes procurem serviços hospitalares de urgência e emergência, onde há um maior fluxo de pessoas, estando os pacientes sujeitos a uma maior exposição ao vírus da COVID-19 ${ }^{18,19}$. Além disso, deixar de atender pacientes em casos de urgências quando não há outro cirurgião-dentista que possa fazê-lo constitui infração ética, podendo o profissional responder por essa omissão ${ }^{22}$.

Por fim, tem-se que uma demanda eletiva, caso não seja tratada, com o tempo pode tornar-se uma urgência ou uma emergência. Por exemplo, um paciente em tratamento ortodôntico, mesmo que por fins estéticos, ao deixar de comparecer às manutenções periódicas do aparelho feitas pelo ortodontista pode enfrentar problemas como necrose pulpar, reabsorção radicular e perda óssea ${ }^{24}$. Então, tendo em vista que a liberdade de convicção de diagnóstico, planejamento e execução de tratamento é um direito profissional $^{22}$, os cirurgiões-dentistas podem realizar quaisquer procedimentos que não tenham sido elencados, mas que o considerem necessário.

\section{Biossegurança e o Uso de Equipamentos de Proteção Individual (EPI)}

A contaminação cruzada em consultórios odontológicos se dá quando há transmissão do vírus entre profissionais e pacientes (e vice-versa), podendo ocorrer também de um paciente para outro, por meio dos instrumentais odontológicos ou dos aerossóis provenientes do tratamento realizado ${ }^{17}$. Para evitar essa situação, ocorreram alterações significativas na rotina dos atendimentos que não puderam ser adiados ${ }^{10}$. Gorro descartável, óculos de proteção, luvas, capote impermeável, propés, protetor facial do tipo face shield e máscara PPF2 ou N95 foram os EPI recomendados para todos os procedimentos odontológicos ${ }^{11,17}$, sendo os dois últimos uma novidade nos protocolos, tendo em vista os EPI utilizados antes do período de pandemia.

Além disso foram aconselhadas estratégias preventivas como: saber identificar caso suspeito da doença por triagem prévia utilizando mensagens ou aplicativos de celulares; orientar o não comparecimento de acompanhantes, salvo nos casos necessários; reduzir o uso de instrumentos rotatórios; reduzir o número de atendimentos por dia, disponibilizando tempo para uma descontaminação cuidadosa do ambiente clínico entre um paciente e outro $^{6,11}$.

Nesse novo cenário, tornou-se imprescindível a capacitação e o treinamento dos profissionais de saúde sobre o uso correto dos EPI. Esse treinamento passou a ser responsabilidade dos serviços de saúde, como as clínicas e consultórios odontológicos, que deveriam oferecê-lo aos cirurgiões-dentistas, técnicos em saúde bucal (TSB) e auxiliares em saúde bucal (ASB), fossem eles funcionários próprios, terceirizados, ou prestadores de serviços temporários ${ }^{11}$.

A escassez de EPI e as condições inadequadas de trabalho resultam em um maior número de casos da doença, comprometendo a dignidade da pessoa humana ao pôr em risco a vida dos pacientes e dos trabalhadores ${ }^{25}$. De acordo com a NR-6, os empregadores são obrigados a fornecer aos seus empregados, gratuitamente, EPI adequados ao risco de exposição a agentes biológicos, em perfeito estado de conservação e funcionamento ${ }^{26}$. A Lei Federal $\mathrm{n}^{\circ} 14.023$, de 8 de julho de 2020, também ratificou esse posicionamento ao determinar que os EPI recomendados pela ANVISA deveriam ser fornecidos aos profissionais que estivessem em contato direto com possíveis portadores da doença ${ }^{27}$, estando entre eles cirurgiões- 
-dentistas, TSB e ASB.

Assim, em casos de ausência de EPI e de condições adequadas de biossegurança e trabalho em clínicas ou consultórios odontológicos, recomenda-se a denúncia na Vigilância Sanitária, órgão competente para esta fiscalização. Trata-se de um direito do profissional recusar-se a exercer a profissão onde as condições de trabalho não sejam seguras, e um dever, apontar falhas nas instituições em que trabalhe, quando as julgar indignas para o exercício da profissão ou prejudiciais ao paciente ${ }^{22}$.

\section{Teleodontologia e Considerações sobre a Resolução CFO-226/2020}

A teleodontologia caracteriza-se como um método facilitado de assistência odontológica à distância, por meio de comunicação remota entre profissional e paciente, visando a promoção de saúde ${ }^{28}$. A discussão sobre a teleodontologia se intensificou durante a pandemia de COVID-19 à medida que ela foi vista como uma possível estratégia para reduzir a circulação de pessoas, diminuir a transmissão do vírus e manter os serviços de saúde funcionando de forma mais segura ${ }^{7}$. Nesse sentido, a ANVISA recomendou, como uma das primeiras medidas de prevenção à contaminação nos serviços odontológicos, a realização de triagem prévia de pacientes com síndrome gripal e o agendamento de consultas, por meio de chamadas telefônicas, aplicativos de mensagens ou videoconferência ${ }^{11}$.

Considerando que no Brasil não há legislação ou normas regulatórias sobre $\mathrm{o}$ assunto ${ }^{7}$, $\mathrm{CFO}$ publicou em 4 de junho de 2020 a Resolução CFO-226, visando dispor sobre o exercício da Odontologia à distância e mediado por tecnologias ${ }^{29}$. De acordo com a resolução, não se pode exercer a Odontologia à distância para fins de consulta, diagnóstico, prescrição ou elaboração de plano de tratamento odontológico. Porém, o telemonitoramento e a teleorientação, durante o estado de calamidade pública declarado pelo Governo Federal, foram admitidos ${ }^{29}$. $\mathrm{O}$ telemonitoramento conceitua-se como o acompanhamento à distância de pacientes que já estão em tratamento, e a teleorientação, como uma triagem prévia com o objetivo de identificar o melhor momento para a realização do atendimento presencial ${ }^{7,29}$.

Entretanto, não se pode afirmar que a Resolução CFO-226/2020 seja efetivamente uma inovação na disciplina ética da prática odontológica à distância (teleodontologia). Isso porque o Código de Ética Odontológica ${ }^{22}$ vigente (Resolução CFO-118/2012) já trazia vedação ética à prática de consulta à distância, nos termos do art. 44, inciso V, o qual caracteriza a conduta de "dar consulta, diagnóstico, prescrição de tratamento ou divulgar resultados clínicos por meio de qualquer veículo de comunicação de massa" como infração ética.

A Resolução CFO-226/2020 reforça, portanto, disposição ética contida no Código de Ética Odontológi- ca, e vem ao encontro dos deveres profissionais de zelar pela saúde e pela dignidade do paciente, e de abster-se da prática de atos que impliquem má conceituação da profissão ou que a mercantilize ${ }^{22}$. Além disso, a resolução vem afirmar o que foi disposto no artigo $7^{\circ}$ da Lei Federal $n^{\circ}$ 5.081 , de 24 de agosto de 1966, que regula o exercício da Odontologia e proíbe a realização de consultas por correspondências, rádio, televisão e meios semelhante ${ }^{30}$.

A discussão sobre a permissão ou não do atendimento odontológico à distância divide opiniões entre os profissionais que exercem a profissão. Segundo Jamal et al. $(2020)^{31}$, a teleodontologia tem papel fundamental na pandemia de COVID-19, pois além de auxiliar os profissionais a realizarem a triagem inicial, também permite que o profissional faça anamnese e avalie fotos e vídeos da condição do paciente, podendo determinar um diagnóstico preliminar e até mesmo iniciar o tratamento através da prescrição medicamentosa, resultando em uma assistência rápida à queixa do paciente. No entanto, as ideias apresentadas pelos autores são contrárias à Resolução CFO-226/2020, que proíbe tais práticas. Já para Wu et al. $(2020)^{21}$, durante a pandemia muitos são os desafios inerentes ao atendimento odontológico, porém a teleodontologia não pode ser vista como uma das soluções, pois esta limita a capacidade de avaliação do paciente, o que leva a um diagnóstico impreciso e, consequentemente, a condutas e prescrições inadequadas. Os autores apontam, também como limitação, a confidencialidade e a privacidade dos dados gerados por meio das teleconsultas, pois muitos meios de comunicação são não criptografados, o que gera alto risco de quebra de sigilo entre profissional e paciente.

\section{Responsabilidade Civil, Penal e Ética do Cirurgião- -Dentista}

A responsabilidade dos cirurgiões-dentistas está relacionada aos atos praticados durante o exercício da profissão. À medida que há o descumprimento de uma de suas obrigações, causando danos ao paciente ou aos seus bens, o profissional poderá responder nas esferas cível, criminal, ética ou administrativa ${ }^{32,33}$. Atualmente, há um aumento progressivo dos casos de judicialização do exercício da Odontologia ${ }^{33}$, e os novos desafios e riscos do atendimento odontológico durante a pandemia de COVID-19 podem contribuir ainda mais para esse aumento.

Na responsabilidade civil, o dano causado ao paciente é proveniente de um ato ilícito profissional, ou seja, uma conduta associada à realização de procedimentos odontológicos, e sua reparação ocorre por meio de ações judiciais indenizatórias ${ }^{34}$. O Código Civil Brasileiro (CC) e o Código de Defesa do Consumidor (CDC) são os dispositivos da legislação brasileira que garantem à vítima $\mathrm{o}$ ressarcimento do prejuízo proveniente do dano ${ }^{32,35,36}$.

$\mathrm{O} \mathrm{CDC}$, ao disciplinar as relações entre prestadores de serviço (cirurgiões-dentistas) e consumidores (pacientes), estabelece em seu artigo $6^{\circ}$ que são direitos do 
consumidor a proteção da vida, saúde e segurança contra os riscos provocados por serviços e a informação adequada e clara. Em seu artigo $8^{\circ}$ ainda traz que os serviços oferecidos não poderão acarretar riscos à saúde ou à segurança dos consumidores, exceto os considerados normais e previsíveis $^{36}$. De acordo com os artigos 186 e 927 do CC, o cirurgião-dentista que durante o exercício da profissão causar algum dano ao paciente em decorrência de ação ou omissão voluntária, negligência ou imprudência fica obrigado a repará-lo. Haverá responsabilidade civil, portanto, quando restarem caracterizados o ato profissional, o dano, o nexo de causalidade (entre o ato profissional e o dano) e a culpa ${ }^{37}$. Assim sendo, caso um paciente contraia o vírus SARS-CoV-2 durante a realização de tratamentos odontológicos, na ausência das condutas adequadas e da informação devida, o cirurgião-dentista responsável pelo tratamento poderá sofrer algum tipo de questionamento. Como se trata de um vírus de circulação comunitária ao nível mundial, e, além disso, de difícil identificação do momento da contaminação, o paciente deverá provar que contraiu o vírus durante o atendimento odontológico. Se assim não o fizer, o nexo de causalidade estará rompido e não será possível imputar a responsabilidade pela contaminação ao profissional e/ou à clínica odontológica.

Em caso de condenação, a valoração do dano para fins indenizatórios torna-se uma incógnita, considerando que o curso da doença, incluindo as sequelas físicas e neurológicas, ainda não está claro ${ }^{38}$. Evidências sugerem que a infecção pelo SARS-CoV-2 pode causar danos cerebrais a longo prazo $^{39}$, doenças vasculares ${ }^{40}$, complicações endócrino-metabólicas ${ }^{41}$ e disfunção pulmonar ${ }^{39}$.

Outro motivo que pode levar à judicialização da prestação de serviços odontológicos em tempos de pandemia é o insucesso do tratamento associado à suspensão dos atendimentos eletivos. Por exemplo, um paciente sob tratamento ortodôntico que tenha seu acompanhamento adiado, caso tenha recidiva ou insatisfação com o resultado final, pode requerer judicialmente uma indenização. Sobre esse aspecto, pontua-se que deve haver um compartilhamento de responsabilidade entre profissional e paciente durante a tomada de decisões, sendo o paciente também responsável pelo resultado do tratamento alcançado $^{42}$; o que se aconselha é que o cirurgião-dentista dê a esse paciente todas as informações necessárias sobre o tratamento, explicitando principalmente os riscos e as consequências da não intervenção e da intervenção para que, devidamente informado, esse paciente possa exercer o seu direito de escolha. Ou seja, é recomendado que o cirurgião-dentista, conforme previsto na Resolução CFO226/2020, adote o telemonitoramento e a teleorientação, devendo estas condutas serem registradas em prontuário. De toda forma, mesmo com o consentimento do paciente em aguardar até um momento seguro para a realização do atendimento, os riscos da interrupção do tratamento em curso não excluem de forma integral a responsabilidade do profissional ${ }^{14}$, sendo necessária a avaliação da conduta.
Em relação à responsabilidade penal, deve-se considerar os atos odontológicos que se enquadram no Código Penal Brasileiro (CP). A possibilidade de um paciente contrair a COVID-19 durante um tratamento odontológico pode motivá-lo a processar o cirurgião-dentista na esfera criminal. O artigo 129 do CP pode embasar este processo, pois determina que é crime ofender a saúde de outrem, estando sujeito o autor a detenção de três meses a um ano. Caso a doença resulte em morte, há um agravante nesta pena, podendo o autor sofrer reclusão de quatro a doze anos. Outro crime que pode embasar a condenação de um cirurgião-dentista no contexto da pandemia é a infração de medida sanitária preventiva, quando o profissional infringir determinação do poder público destinada a impedir a propagação da doença, estando sujeito o réu à pena de detenção de um mês a um ano e multa. Por ser cirurgião-dentista, a pena, se caracterizada a conduta criminosa, será aumentada de um terço ${ }^{43}$. Ou seja, caso haja algum impedimento legal para o exercício da profissão e mesmo assim o cirurgião-dentista o faça, ele pode responder criminalmente por essa atitude.

No que se refere à responsabilidade ética, a aplicação de penalidades administrativas aos profissionais se dá mediante a adoção de condutas (ativas ou omissivas) classificadas como infrações éticas no Código de Ética Odontológica (CEO). E de acordo com o CEO, constitui dever fundamental do cirurgião-dentista zelar pela saúde e pela dignidade do paciente, bem como promover a saúde coletiva $^{22}$. Desse modo, um paciente que se sinta prejudicado pelo cirurgião-dentista ao se contaminar após a consulta também pode processá-lo na esfera ética.

Compreende-se que a judicialização da Odontologia diante dos casos de COVID-19 pode ser minimizada se medidas preventivas forem adotadas, como seguir toda a legislação relacionada ao funcionamento dos serviços odontológicos, cumprimento do dever de informação, e confecção adequada da documentação odontológica ${ }^{33}$, pois é através dela que o cirurgião-dentista poderá romper o nexo de causalidade entre o seu ato e a doença do paciente.

\section{Prontuário Odontológico e Consentimento Livre e Esclarecido: medidas preventivas}

O prontuário odontológico é o conjunto de documentos obtidos durante o tratamento odontológico ${ }^{37,42}$, sendo obrigatória a sua elaboração, guarda e atualização ${ }^{22,44}$. É considerado o principal instrumento de defesa na análise de responsabilização profissional, pois caso possua informações claras e completas, informará como foi a conduta profissional ${ }^{37,45}$. Em lides judiciais ou ético-disciplinares envolvendo a possível infecção pelo vírus SARS-CoV-2 em atendimento odontológico, o cirurgião-dentista poderá comprovar a sua atuação segura ao apresentar um prontuário informando que foram utilizadas as medidas de biossegurança preconizadas, afastando o 
defeito do serviço e, consequentemente, rompendo o nexo de causalidade entre a doença e ato odontológico.

Para isso, faz-se necessário anotar os meios utilizados que visam a impedir a contaminação cruzada, tais como: quais EPI utilizados; qual o intervalo de atendimento entre os pacientes; como foi realizada a descontaminação e desinfecção do ambiente clínico e; como foi realizada a esterilização dos materiais e instrumentais. Deve-se registrar que os atendimentos ocorreram durante o período da pandemia para que as condutas tomadas sejam avaliadas com a perspectiva do momento.

E no tocante à manutenção desta documentação, de acordo com o CDC, o consumidor (paciente) tem até cinco anos para ingressar com ação judicial contra o prestador de serviço (cirurgião-dentista) devido à insatisfação com o tratamento, mas que esse prazo só começa a partir do conhecimento do dano ${ }^{36,44}$. Como já dito, ainda não se sabe quais são as sequelas da COVID-19, então, mesmo que o paciente saiba da doença, os danos a longo prazo são desconhecidos, ou seja, recomenda-se a guarda do prontuário odontológico, quando possível, para além do prazo mínimo obrigatório de 20 anos a partir do último registro, como regido pela Lei Federal $n^{\circ} 13.787$, de 27 de dezembro de $2018^{46}$, que trata de prontuários digitais.

O termo de consentimento livre e esclarecido (TCLE), por sua vez, é o documento que tem como uma de suas funções informar ao paciente quais são os riscos que podem ocorrer durante a realização de determinado tratamento ${ }^{47}$. De acordo com o artigo $6^{\circ}$ do CDC, é direito básico o acesso a informações adequadas e claras sobre $\mathrm{o}$ procedimento odontológico a ser realizado ${ }^{36}$.

A falha no dever de informação poderá ser entendida como uma conduta omissiva do profissional ${ }^{47}$, podendo gerar o dever de indenizar, caso associada a algum dano ao paciente. E no contexto da pandemia de COVID-19, torna-se ainda mais importante explicar para o paciente quais os riscos de se realizar um tratamento odontológico, por se tratar de uma doença que pode levar ao óbito. Além disso, caso o paciente opte por adiar o tratamento odontológico ou por continuá-lo em um momento após a pandemia, deve-se deixar bem claro quais são as consequências da não intervenção ${ }^{14}$.

Recomenda-se deixar claro para o paciente, por meio remoto que possa ser documentado, todos os riscos de contaminação a que ele se expõe durante o tratamento e ao se deslocar para o consultório odontológico e quais são os riscos de não fazer o tratamento e esperar um momento posterior ${ }^{14}$. Caso o paciente opte por continuar o tratamento, sugere-se a elaboração do TCLE abordando o procedimento odontológico que será realizado e a possibilidade de esse paciente contrair a COVID-19. Recomenda-se informar detalhadamente quais são as medidas adotadas dentro do consultório odontológico para controle da infecção, deixando claro que tudo o que pode ser feito durante o atendimento para segurança do paciente e toda a equipe está sendo realizado ${ }^{14}$, porém, que não há garantias de não contaminação, seja em seu trajeto seja no próprio ambiente do consultório.

\section{CONSIDERAÇÕES FINAIS}

Embora o distanciamento social seja considerado uma das estratégias principais para prevenir a transmissão viral durante a pandemia de COVID-19, garantir o funcionamento de serviços odontológicos é imprescindível para promoção da saúde populacional. Assim, conclui-se que o atendimento odontológico em tempos de pandemia é viável, quando necessário e permitido. Seguindo todos os preceitos éticos e legais para atuação, o profissional pode afastar a possibilidade de se envolver em questionamentos provenientes desses atendimentos. Há de se ressaltar que no momento de redação deste trabalho, a pandemia ainda está em curso, ou seja, os dispositivos legais aqui abordados estão sendo constantemente atualizados e/ ou modificados.

Pinheiro FA, Coltri MV, Pereira JGD, Silva RHA. Ethical and legal issues in dental practice during the COVID-19 pandemic. Saúde, Ética \& Justiça. 2021;26(1):27-35.

ABSTRACT: In March 2020, the World Health Organization declared the COVID-19 pandemic, a disease caused by the SARS-Cov-2 virus. As a strategy to minimize its transmission, public agencies and health entities have published resolutions, technical notes, recommendations, and protocols regarding dental practice. Considering that the suggested changes were not related to previous legal recommendations regarding cases of lawsuits in dental practice, this study aimed to discuss the effect of the new COVID-19 regulations on dental practice based on ethical and legal dispositions, supporting a safe environment for practicing dentistry. In conclusion, even though social distancing is considered one of the most efficient strategies to prevent viral transmission during the pandemic, dental services are essential for public health. Therefore, dental care is viable when needed and permitted. If all ethical and legal principles are adhered to, the professional may discard the possibility of getting involved in lawsuits that might occur due to practicing dentistry during this time.

KEY WORDS: COVID-19; Dentistry; Legislation, Dental; Ethics, Dental. 


\section{REFERÊNCIAS}

1. Sun J, He WT, Wang L, Lai A, Ji X, Zhai X, et al. COVID-19: Epidemiology, evolution, and cross-disciplinary perspectives. Trends Mol Med. 2020;26(5):483-95. DOI: http://dx.doi.org/10.1016/j.molmed.2020.02.008

2. Fallahi HR, Keyhan SO, Zandian D, Kim SG, Cheshmi B. Being a front-line dentist during the Covid-19 pandemic: a literature review. Maxillofac Plast Reconstr Surg. 2020;42(1):12. DOI: http://dx.doi.org/10.1186/s40902020-00256-5

3. Guo YR, Cao QD, Hong ZS, Tan YY, Chen SD, Jin HJ, et al. The origin, transmission and clinical therapies on coronavirus disease 2019 (COVID-19) outbreak - an update on the status. Military Med Res. 2020;7(1):11. DOI: http:// dx.doi.org/10.1186/s40779-020-00240-0

4. To KK, Tsang OT, Yip CC, Chan KH, Wu TC, Chan JM, et al. Consistent detection of 2019 novel Coronavirus in saliva. Clin Infect Dis. 2020;71(15):841-3. DOI: http:// dx.doi.org/10.1093/cid/ciaa149

5. Braz-Silva PH, Pallos D, Giannecchini S, To KK. SARS-CoV-2: What can saliva tell us? [letter]. Oral Dis. 2021;27(Suppl 3):746-7. DOI: http://dx.doi.org/10.1111/ odi. 13365

6. Peng X, Xu X, Li Y, Cheng L, Zhou X, Ren B. Transmission routes of 2019-nCoV and controls in dental practice. Int J Oral Sci. 2020;12(1):9. DOI: http://dx.doi.org/10.1038/ s41368-020-0075-9

7. Caetano R, Silva AB, Guedes ACCM, Paiva CCN, Ribeiro GR, Santos DL, et al. Desafios e oportunidades para telessaúde em tempos da pandemia pela COVID-19: uma reflexão sobre os espaços e iniciativas no contexto brasileiro. Cad Saúde Pública. 2020;36(5):e00088920. DOI: https://doi.org/10.1590/0102-311x00088920

8. Caprioglio A, Pizzetti GB, Zecca PA, Fastuca R, Maino G, Nanda R. Management of orthodontic emergencies during 2019-NCOV. Prog Orthod. 2020;21(1):10. DOI: https://doi. org/10.1186/s40510-020-00310-y

9. Matson MR, Giorgi MS, Netto CA, Souza CO, Springer C, Sampaio EM, et al. A viable dentistry after Covid-19. Rev Assoc Paul Cir Dent. 2020;74(2):164-79.

10. Franco JB, Camargo AR, Peres MPSM. Dental care in the COVID-19 era: recommendations for dental procedures and professionals. Rev Assoc Paul Cir Dent. 2020;74(1):18-2.

11. Agência Nacional de Vigilância Sanitária (ANVISA). Nota técnica GVIMS/GGTES/ANVISA n ${ }^{\circ} 04 / 2020$. Orientações para serviços de saúde: medidas de prevenção e controle que devem ser adotadas durante a assistência aos casos suspeitos ou confirmados de infecção pelo novo coronavírus (SARSCoV-2) [Internet]. [Acesso em 2020 out. 27]. Disponível em: https://www.gov.br/anvisa/pt-br/centraisdeconteudo/ publicacoes/servicosdesaude/notas-tecnicas/nota-tecnicagvims_ggtes_anvisa-04_2020-25-02-para-o-site.pdf

12. American Dental Association. What Constitutes a Dental
Emergency? [Internet]. Chicago; 2020 [Acesso em 2020 out. 17]. Disponível em: https://success.ada.org/en

13. U.S. Department of Health and Human Services. Centers for Disease Control and Prevention. Interim Infection Prevention and Control Guidance for Dental Settings During the Coronavirus Disease 2019 (COVID-19) Pandemic [Internet]. [Acesso em 2020 abr. 08]. Disponível em: https:/www.cdc.gov/coronavirus/2019-ncov/hcp/ dental-settings.html\#print

14. Associação Brasileira de Ética e Odontologia Legal. Orientações odontolegais com relação à retomada de atividades de ensino [Internet]. [Acesso em 2020 out. 17]. Disponível em: https://contatoabol.wixsite.com/abol/ single-post $/ 2020 / 07 / 28 /$ orienta $\% \mathrm{C} 3 \% \mathrm{~A} 7 \% \mathrm{C} 3 \% \mathrm{~B} 5$ esodontolegais-com-rela $\% \mathrm{C} 3 \% \mathrm{~A} 7 \% \mathrm{C} 3 \% \mathrm{~A} 30-\% \mathrm{C} 3 \% \mathrm{~A} 0$ retomada-de-atividades-de-ensino

15. Brasil. Ministério da Saúde. Nota técnica no 16/2020-CGSB/ DESF/SAPS/MS. COVID-19 e atendimento odontológico no SUS [Internet]. [Acesso em 2020 out. 17]. Disponível em: http://www.crosp.org.br/uploads/arquivo/295c9c1440 9db20cb63c862bb07ce0e4.pdf

16. Comitê de Odontologia Associação de Medicina Intensiva Brasileira/Conselho Federal de Odontologia (AMIB/CFO) de enfrentamento ao COVID-19. Recomendações AMIB/ CFO para atendimento odontológico COVID- 19 [Internet]. [Acesso em 2020 out 17]. Disponível em: https://website. cfo.org.br/wp-content/uploads/2020/06/recomendacoesamib-cfo-junho- 2020.pdf

17. Conselho Regional de Odontologia de São Paulo. Orientação de biossegurança: adequações técnicas em tempos de COVID-19 [Internet]. [Acesso em 2020 out 17]. Disponível em: http://www.crosp.org.br/uploads/arquivo/7 47df5ff505e7beff33c1a5ff5d6f12a.pdf

18. Long RH, Ward TD, Pruett ME, Coleman JF, Plaisance MC Jr. Modifications of emergency dental clinic protocols to combat COVID-19 transmission. Spec Care Dentist. 2020;40(3):219-26. DOI: https://doi.org/10.1111/scd.12472

19. Odeh ND, Babkair H, Abu-Hammad S, Borzangy S, Abu-Hammad A, Abu-Hammad O. COVID-19: Present and future challenges for dental practice. Int $\mathrm{J}$ Environ Res Public Health. 2020;17(9):3151. DOI: https://doi. org/10.3390/ijerph17093151

20. Brasil. Presidência da República, Subchefia para Assuntos Jurídicos. Lei no 4.324 de 14 de abril de 1964. Institui o Conselho Federal e os Conselhos Regionais de Odontologia, e dá outras providências [Internet]. Brasília, DF; 1964. [Acesso em 2020 out. 17]. Disponível em: http:// www.planalto.gov.br/ccivil_03/leis/1950-1969/14324.htm

21. Wu KY, Wu DT, Nguyen TT, Tran SD. COVID-19's impact on private practice and academic dentistry in North America. Oral Dis. 2021;27(Suppl 3):684-7. DOI: https:// doi.org/10.1111/odi.13444

22. Brasil. Conselho Federal de Odontologia. Resolução $n^{0}$ 
118 de 11 de maio de 2012. Revoga o Código de Ética Odontológica aprovado pela Resolução CFO-42/2003 e aprova outro em substituição [Internet]. [Acesso em 2020 out. 17]. Disponível em: http://cfo.org.br/wp-content/ uploads/2009/09/codigo_etica.pdf

23. The Ethics Subcommittee of the Council on Ethics, Bylaws and Judicial Affairs. Ethical practice during the COVID-19 pandemic. J Am Dent Assoc. 2020;151(5):377-8. DOI: https://doi.org/10.1016/j.adaj.2020.03.038

24. Westley H. Risks and complications in orthodontic treatment. Dent Nurs. 2010;6(6):318-21.

25. Carvalho EC, Souza PHDO, Varella TCMML, Souza NVDO, Farias SNP, Soares SSS. Pandemia da COVID-19 e a judicialização da saúde: estudo de caso explicativo. Rev Latino-Am Enfermagem [Internet]. 2020 [Acesso em 2020 out. 17];28:e3354. Disponível em: https://www.scielo.br/j/ rlae/a/Z9L5sggXdBpqM5bdcywg9xn/?lang=pt\&format=p df. DOI: https://doi.org/10.1590/1518-8345.4584.3354

26. Brasil. Ministério do Trabalho. Portaria MTb no 3.214 de 08 de junho de 1978. NR 6 - Equipamento de proteção individual - EPI [Internet]. [Acesso em 2020 out 17]. Disponível em: http://acesso.mte.gov.br/data/files/8A7C8 16A4A5E01F7014A9C78ED9D2942/06\%20-\%20NR-06. pdf

27. Brasil. Presidência da República, Subchefia para Assuntos Jurídicos. Lei $\mathrm{n}^{\circ} 14.023$ de 8 de julho de 2020. Altera a Lei $\mathrm{n}^{\mathrm{o}} 13.979$ para determinar a adoção de medidas imediatas que preservem a saúde e a vida de todos os profissionais considerados essenciais ao controle de doenças e à manutenção da ordem pública, durante a emergência de saúde pública decorrente do coronavírus responsável pelo surto de 2019 [Internet]. Brasília, DF; 2020. [Acesso em 2020 out. 17]. Disponível em: http://www.planalto.gov.br/ ccivil 03/ ato2019-2022/2020/lei/L14023.htm

28. Caldarelli PG, Haddad AE. Teledentistry in consonance with the National Curriculum Guidelines in the development of professional competencies. Rev ABENO. 2016;16(2):2532.

29. Brasil. Conselho Federal de Odontologia. Resolução $n^{\circ}$ 226 de 04 de junho de 2020. Dispõe sobre o exercício da Odontologia a distância, mediado por tecnologias, e dá outras providências [Internet]. [Acesso em 2020 out. 27]. Disponível em: http://sistemas.cfo.org.br/visualizar/atos/ RESOLUÇÃO/SEC/2020/226

30. Brasil. Presidência da República, Subchefia para Assuntos Jurídicos. Lei $\mathrm{n}^{\circ} 5.081$ de 24 de agosto de 1966. Regula o exercício da Odontologia [Internet]. Brasília, DF; 1966. [Acesso em 2020 out. 27]. Disponível em: http://www. planalto.gov.br/ccivil_03/leis/15081.htm

31. Jamal M, Shah M, Almarzooqi SH, Aber H, Khawaja S, El Abed R, et al. Overview of transnational recommendations for COVID-19 transmission control in dental care settings. Oral Dis. 2021;27(Suppl 3):655-64. DOI: https://doi. org/10.1111/odi.13431

32. Terada ASSD, Galo R, Silva RHA. Civil liability of the dental surgeon: professionals' knowledge. Arq Odontol [Internet]. 2014 [Acesso em 2020 out. 27];50(2):92-7.

33. Ferreira MR, Terada ASSD, Araujo LG, Paz DC, Dezem TU, Silva RHA. Correlação entre reclamações de consumidores e ações judiciais por falhas na prestação de serviços odontológicos no estado de São Paulo, Brasil. Rev Bras Odontol Leg RBOL. 2018;5(1):30-9. DOI: https://doi. org/10.21117/rbol.v5i1.147

34. Jacometti V, Coltri MV, Santos TS, Silva RHA. Procedimento de bichectomia: uma discussão sobre os aspectos éticos e legais em odontologia. Rev Bras Cir Plást. 2017;32(4):616-23. DOI: https://doi.org/10.5935/21771235.2017RBCP0100

35. Brasil. Presidência da República, Subchefia para Assuntos Jurídicos. Lei ${ }^{\circ} 10.406$ de 10 de janeiro de 2002. Institui o Código Civil [Internet]. Brasília, DF; 2002. [Acesso em 2020 out. 17]. Disponível em: http://www.planalto.gov.br/ ccivil_03/leis/2002/L10406compilada.htm

36. Brasil. Presidência da República, Subchefia para Assuntos Jurídicos. Lei $n^{\circ} 8.078$ de 11 de setembro de 1990. Dispõe sobre a proteção do consumidor e dá outras providências [Internet]. Brasília, DF; 1990. [Acesso em 2020 out. 20]. Disponível em: http://www.planalto.gov.br/ccivil_03/leis/ 18078compilado.htm

37. Benedicto EN, Lages LHR, Oliveira OF, Silva RHA, Paranhos LR. The importance of the correct preparation of dental records. Odonto (São Bernardo do Campo). 2010;18(36):41-50

38. Salehi S, Reddy S, Gholamrezanezhad A. Long-term pulmonary consequences of coronavirus disease 2019 (COVID-19): what we know and what to expect. J Thorac Imaging. 2020;35(4):W87-9. DOI: https://doi.org/10.1097/ RTI.0000000000000534

39. Heneka MT, Golenbock D, Latz E, Morgan D, Brown R. Immediate and long-term consequences of COVID-19 infections for the development of neurological disease. $\mathrm{Alz}$ Res Therapy. 2020;12(1):69. DOI: https://doi.org/10.1186/ s13195-020-00640-3

40. Connors JM, Levy JH. COVID-19 and its implications for thrombosis and anticoagulation. Blood. 2020;135(23):203340. DOI: https://doi.org/10.1182/blood.2020006000

41. Mongioì LM, Barbagallo F, Condorelli RA, Cannarella R, Aversa A, La Vignera S, et al. Possible long-term endocrinemetabolic complications in COVID-19: lesson from the SARS model. Endocrine. 2020;68(3):467-70. DOI: https:// doi.org/10.1007/s12020-020-02349-7

42. Silva RHA. Orientação profissional para o cirurgiãodentista: ética e legislação. $1^{\mathrm{a}}$ ed. São Paulo: Santos; 2010.

43. Brasil. Presidência da República, Subchefia para Assuntos Jurídicos. Decreto-lei no 2.848 de 7 de dezembro de 1940. Código Penal [Internet]. Rio de Janeiro, RJ; 1940. [Acesso em 2020 out. 27]. Disponível em: http://www.planalto.gov. br/ccivil_03/decreto-lei/del2848compilado.htm

44. Coltri MV, Silva RHA. Prontuário do paciente: comentários 
Pinheiro FA et al. Reflexões éticas e legais sobre a prática odontológica em tempos de pandemia de COVID-19.

à Lei $\mathrm{n}^{\mathrm{o}}$ 13.787/2018. Rev Bras Odontol Leg RBOL. 2019;6(2):89-105. DOI: https://doi.org/10.21117/rbol. v6i2.253

45. Almeida SM, Carvalho SPM, Radicchi R. Aspectos legais da documentação odontológica: uma revisão sobre a validade legal, privacidade e aceitação no meio jurídico. Rev Bras Odontol Leg RBOL. 2017;4(2):55-64. DOI: https://doi.org/10.21117/rbol.v4i2.96

46. Brasil. Presidência da República, Subchefia para Assuntos Jurídicos. Lei $\mathrm{n}^{\mathrm{o}} 13.787$ de 27 de dezembro de 2018
Dispõe sobre a digitalização e a utilização de sistemas informatizados para a guarda, o armazenamento e o manuseio de prontuário de paciente [Internet]. Brasília, DF; 2018. [Acesso em 2020 out. 17]. Disponível em: http:// www.planalto.gov.br/ccivil_03/_ato2015-2018/2018/lei/ L13787.htm

47. Silva DMB, Bruno KF, Praxedes LR, Tolentino PHMP. Proposta de termo de consentimento livre e esclarecido em endodontia regenerativa. Rev Bras Odontol Leg RBOL. 2020;7(2):33-42. DOI: https://doi.org/10.21117/rbolv7n22020-293

Recebido em: 07/05/2021

Aprovado em: 19/05/2021 